\title{
Evaluations of the Effects of Extremely Low-Frequency Electromagnetic Fields on Growth and Antibiotic Susceptibility of Escherichia coli and Pseudomonas aeruginosa
}

\author{
B. Segatore, D. Setacci, F. Bennato, R. Cardigno, G. Amicosante, and R. Iorio \\ Department of Biomedical Sciences and Technologies, University of L'Aquila, 67100 L'Aquila, Italy \\ Correspondence should be addressed to R. Iorio, riorio@cc.univaq.it
}

Received 5 December 2011; Accepted 26 January 2012

Academic Editor: Barbara H. Iglewski

Copyright (C) 2012 B. Segatore et al. This is an open access article distributed under the Creative Commons Attribution License, which permits unrestricted use, distribution, and reproduction in any medium, provided the original work is properly cited.

\begin{abstract}
We aimed to investigate the effects of exposure to extremely low-frequency electromagnetic fields $(2 \mathrm{mT} ; 50 \mathrm{~Hz})$ on the growth rate and antibiotic sensitivity of E. coli ATCC 25922 and P. aeruginosa ATCC 27853. The electromagnetic field treatment significantly influenced the growth rate of both strains when incubated in the presence of subinhibitory concentrations of kanamycin $(1 \mu \mathrm{g} / \mathrm{mL})$ and amikacin $(0.5 \mu \mathrm{g} / \mathrm{mL})$, respectively. In particular, at 4,6 , and $8 \mathrm{~h}$ of incubation the number of cells was significantly decreased in bacteria exposed to electromagnetic field when compared with the control. Additionally, at $24 \mathrm{~h}$ of incubation, the percentage of cells increased ( . aeruginosa $\sim 42 \%$; E. coli $\sim 5 \%$ ) in treated groups with respect to control groups suggesting a progressive adaptive response. By contrast, no remarkable differences were found in the antibiotic susceptibility and on the growth rate of both bacteria comparing exposed groups with control groups.
\end{abstract}

\section{Introduction}

In the modern society, greater use of technologies leads to increasing exposure to extremely low-frequency (ELF) electromagnetic fields (EMFs) generated by structures and appliances such as power lines and ordinary devices used inside house and work places. As consequence, the effects of ELF-EMFs on the biological functions of living organisms represent an emerging area of interest with respect to environmental influences on human health. In latest years, several studies have been performed to verify direct effects exerted by ELF-EMF on cell functions. Although results have been somewhat controversial, a variety of cell responses have been observed involving proliferation and differentiation [1-10], gene expression [11-14], modulation of the membrane receptors functionality [15-20], apoptosis [21-23], alteration in ion homeostasis $[1,6,13,24-26]$, and free radicals generation $[25,27-30]$.

Bacteria have also been used in the studies with ELFEMF [31-50]. In particular, it has been demonstrated that
ELF-EMF can negatively $[34,37,42,45,50]$ or positively [ 41 , $42,45,47,48$ ] affect functional parameters (cell growth and viability) and bacteria antibiotic sensitivity depending on physical parameters of the electromagnetic field (frequency and magnetic flux density) applied, the time of the exposure, and/or the type of bacteria cells used. The possibility of a synergistic and/or antagonistic effect evoked by the combination of the appropriately patterned magnetic fields and specific antibiotics deserves special attention in light of the risk that antimicrobial resistance poses to public health. Bacteria are becoming increasingly resistant to almost all presently available antibiotics and this aspect is becoming a worldwide problem of highest significance $[51,52]$. According to these considerations, the study of effects of ELF-EMF on bacteria is essential not only for investigation of environmental stress influences on biological systems, but also to explore the possibility of controlling the sensitivity of bacteria toward antibiotics in the environment or in clinical laboratories.

We have therefore attempted to investigate the possible influence of ELF-EMF on growth and antibiotic sensitivity 


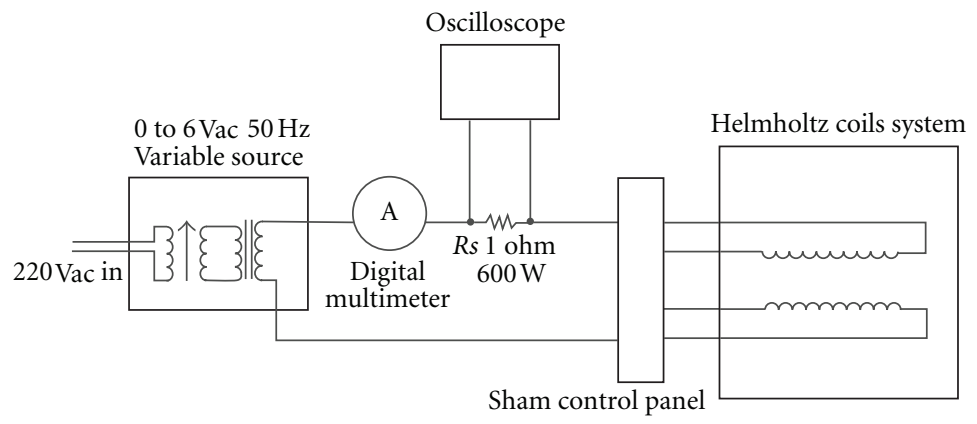

FIgURE 1: Experimental apparatus employed for oscillating magnetic field generation.

of reference strains. To this end, we exposed E. coli ATCC 25922 and P. aeruginosa ATCC 27853 to an ELF-EMF with a sinusoidal waveform of $2 \mathrm{mT}$ amplitude and frequency of $50 \mathrm{~Hz}$, commonly produced in urban environments and in work places. These representative strains were chosen as examples of well-characterized Gram-negative bacteria, widely distributed in the environment and clinically relevant in nosocomial infections. Therefore, we evaluated the in vitro effect of ELF-EMF on the growth rate and antibiotic sensitivity of these strains. In particular, we examined the biological response of exposed cells to kanamycin and amikacin, wellknown inhibitors of protein synthesis, incubating bacteria in the presence of subinhibitory concentration of these antibiotics.

\section{Materials and Methods}

2.1. Strains. The international reference strains Escherichia coli ATCC 25922 and Pseudomonas aeruginosa ATCC 27853 were used for the experiments.

2.2. Antimicrobial Agents. Kanamycin, amikacin, ampicillin, and ceftazidime were purchased from Sigma Chemical (St. Louis, MO); the other study compounds (levofloxacin, cefazolin, ceftriaxone, and moxalactam) were obtained from the respective manufacturers.

2.3. Electromagnetic Field Exposure System. The exposure system consisted of an apparatus containing a pair of Helmholtz coils, a waveform generator, and a current amplifier (Figure 1). In our experiments, for the magnetic field generation we employed a pair of Helmholtz coils, with mean radius of $13.0 \pm 0.5 \mathrm{~cm}$. In each coil the number of turns was 800 with a $2 \mathrm{~mm}^{2}$ wire giving a resulting resistance of $2.4 \Omega$ and an inductance of $39 \pm 1 \mathrm{mH}$. The mean vertical distance between the coils was $13.5 \pm 0.5 \mathrm{~cm}$. The uniformity of the electromagnetic field was better than $1 \%$ within a cylindrical region that allowed a simultaneous exposure of a stack of four culture plates (Falcon multiwell plate; 96 wells) or twelve tubes of bacteria $(20 \mathrm{~mL}$ glass tubes; effective sensitive volume ranging from 5 to $10 \mathrm{~mL}$ ). This feature was in good agreement with the computation of the field distribution and homogeneity calculated by a Laplace equation simulation programme, which take into consideration the finite dimensions of coils. The generator was able to generate an effective magnetic field in the range $0-4 \mathrm{mT}$, with a sinusoidal wave of frequency of $50 \mathrm{~Hz}$. The magnetic flux density (B) at the centre of coils was measured with an FW gaussmeter (Model 912, RFL Industries, Boonton, NJ) and B was adjusted by varying the coil current. The wave shape was visualized by an oscilloscope (Kikisui COS5020) and the current flowing through the systems controlled by a digital multimeter (Agilent 34401A). The exposure system was put in an incubator at $37.0 \pm 0.5^{\circ} \mathrm{C}$. According the different connections, the current could either flow in the same direction or in the opposite direction (sham system), where the magnetic flux density is theoretically zero. In preliminary experiments (sham field experiments), we excluded any influence of the experimental device on environmental parameters such as temperature or gases tension. The frequency and flux density of the sinusoidal EMF were maintained at $50 \mathrm{~Hz}$ and $2.0 \mathrm{mT}$, respectively. To control the temperature, a thermometric sensor (Fluke 51-II, Fluke, WAQ3) was placed inside the Helmholtz coils system during the experiments measuring a constant temperature of $37.0 \pm 0.3^{\circ} \mathrm{C}$. Each sample, resuspended in the appropriate medium, was incubated in the presence (ELFEMF exposed group) or absence (control group) of ELFEMF. The ELF-EMF exposed group was placed in the core of the solenoid where a homogeneous sinusoidal magnetic field was generated, while control group was placed in a separate incubator.

2.4. Susceptibility Tests. Minimal Inhibitory Concentrations (MICs) were performed by conventional broth microdilution procedures in $0.1 \mathrm{~mL}$ volumes of Mueller Hinton broth. A final inoculum of $5 \times 10^{5}$ colony-forming units (CFUs)/mL was used, as suggested by CLSI [53]. ELFEMF exposed groups and control groups were incubated for $20 \mathrm{~h}$ at $37^{\circ} \mathrm{C}$ and then examined for cell growth. MIC results were recorded as the dilution value at which no visible growth occurred. As the growth curves were performed in glass tubes, MICs values were also determined by the broth macrodilution method (according to CLSI) using the same experimental parameters as those used for microdilution procedures. Data reported in Table 1 are referred to MIC values obtained using macrodilution procedures. 
TABLE 1: MIC values ( $\mu \mathrm{g} / \mathrm{mL})$ for E. coli and P. aeruginosa exposed or not exposed to ELF-EMF (sinusoidal wave; $2 \mathrm{mT} ; 50 \mathrm{~Hz}$ ).

\begin{tabular}{|c|c|c|c|c|}
\hline \multicolumn{5}{|c|}{ Strains } \\
\hline & E. coli & E. coli/ELF-EMF & $P$. aeruginosa & P. aeruginosa/ELF-EMF \\
\hline \multicolumn{5}{|c|}{ Antibiotics } \\
\hline KAN & 4 & 4 & nd & nd \\
\hline AMK & 1 & 1 & 2 & 2 \\
\hline AMP & 8 & 8 & nd & nd \\
\hline CFZ & 4 & 4 & nd & nd \\
\hline CAZ & 0.12 & 0.12 & 2 & 2 \\
\hline CRO & 0.12 & 0.12 & 32 & 32 \\
\hline MOX & 0.12 & 0.12 & 32 & 32 \\
\hline LVX & 0.03 & 0.03 & 4 & 4 \\
\hline
\end{tabular}

KAN: kanamycin; AMK: amikacin; AMP: ampicillin; CFZ: cefazolin; CAZ: ceftazidime; CRO: ceftriaxone; MOX: moxalactam; LVX: levofloxacin; E. coli: ATCC 25922; P. aeruginosa: ATCC 27853.

2.5. Growth Curves. The growth rates of $E$. coli and $P$. aeruginosa were carried out according to the method of Schoenknecht et al. [54]. ELF-EMF exposed groups and control groups were incubated in the presence or in the absence of subinhibitory concentration $(1 / 4 \times \mathrm{MIC})$ of $1 \mu \mathrm{g} / \mathrm{mL}$ kanamycin $(E$. coli) and $0.5 \mu \mathrm{g} / \mathrm{mL}$ amikacin $(P$. aeruginosa). Each sample (starting inoculum of about $5 \times 10^{5} \mathrm{CFU} / \mathrm{mL}$ opportunely diluted in $10 \mathrm{~mL}$ of Mueller Hinton broth) was incubated for $24 \mathrm{~h}$. At $0,4,6$, and $8 \mathrm{~h}$ of incubation samples were immediately vortexed for $15 \mathrm{sec}$ and opportunely diluted. To test $24 \mathrm{~h}$ sample, at $20 \mathrm{~h}$ of incubation bacteria were vortexed for $15 \mathrm{sec}$ and additionally reincubated for $4 \mathrm{~h}$. At the end of incubation sample was immediately vortexed for $15 \mathrm{sec}$ and opportunely diluted. After dilutions, one hundred microliters of each sample were plated and incubated for additionally $24 \mathrm{~h}$ at $37^{\circ} \mathrm{C}$. At the end of the incubation the colony counts were performed and data were reported on semilog paper with the survivor colony count on the ordinate in logarithmic scale and the time in the abscissa in arithmetic scale.

2.6. Statistical Analysis. All experiments were replicated at least three times and the statistical significance of each difference observed among the mean values was determined by standard error analysis. The Sigma Stat 2.03 (SPSS, Chicago, IL) was used to test the statistical significance of differences between group means (one-way ANOVA followed by Tukey's test); $P<0.05$ was considered to be statistically significant.

\section{Results and Discussion}

We tested E. coli and P. aeruginosa for their in vitro susceptibility to various antibiotics in the presence of ELF-EMF. On the basis of their different mechanism of action we evaluated the following classes of antibiotics: kanamycin, amikacin, ampicillin, cefazolin, ceftazidime, ceftriaxone, moxalactam, and levofloxacin.

Data obtained with untreated and treated cells did not reveal any significant changes in MIC values (Table 1) suggesting that under our experimental conditions longterm exposure $(24 \mathrm{~h})$ to ELF-EMF did not influence the degree of antibiotic susceptibility of E. coli and P. aeruginosa. We next examined the effect of ELF-EMF on the growth rate of bacteria. As shown in Figure 2, at each time point investigated, no remarkable differences were found in the rate of bacteria growth comparing exposed groups with control groups.

Our data do not support previous observations on the ability of ELF-EMF to induce changes of cell growth and antibiotic sensitivity that were reported for E. coli $[37,39$, $42,45-48,55]$ and other strains $[38,39,56]$. In particular, it has been found that viability of different types of bacteria (Escherichia coli, Leclercia adecarboxylata, and Staphylococcus aureus) was affected after exposure to an ELF-EMF of $10 \mathrm{mT}$ amplitude and frequency of $50 \mathrm{~Hz}$ [37]. Particularly, Gram-negative E. coli and Leclercia adecarboxylata achieved about $60-70 \%$ of colony forming units (CFU) number after exposure compared to the control ones. ELF-EMF $(10 \mathrm{mT} ; 50 \mathrm{~Hz})$ has lethal effect on bacteria Paracoccus denitrificans, but without changes in denitrification activity [39]. Additionally, Fojt and colleagues [38] have not observed any change in bacterial morphology neither of E. coli K12 (rod-like) nor of $P$. denitrificans CCM 982 (spherical) after exposure for $1 \mathrm{~h}$ to ELF-EMF $(10 \mathrm{mT}, 50 \mathrm{~Hz})$ suggesting that bacteria shape does not play any important role in the interaction with magnetic field. On the contrary, it has been demonstrated that short-term exposure (20-120 min) to an ELF-EMF with a sinusoidal waveform of amplitude ranging from 0.1 to $1 \mathrm{mT}$ and frequency of $50 \mathrm{~Hz}$ affected both cell viability and morphology of cultured E. coli ATCC 700926 [47]. In these experimental conditions, electromagnetic field also induced transcriptional changes and the acquisition of resistance to Cephalosporins (Cefuroxime and Ceftazidime). The influence of ELF-EMF on E. coli cultures was also studied by Justo and colleagues [42] which have found that cell growth could be altered (stimulated or inhibited) under magnetic field ( $100 \mathrm{mT}$; $50 \mathrm{~Hz}$ ) effects. Further, the exposure of E. coli ATCC 25992 to an ELF-EMF of $2 \mathrm{mT}$ amplitude and frequency of $50 \mathrm{~Hz}$ caused pronounced changes in the growth characteristic curves, morphology, structural 


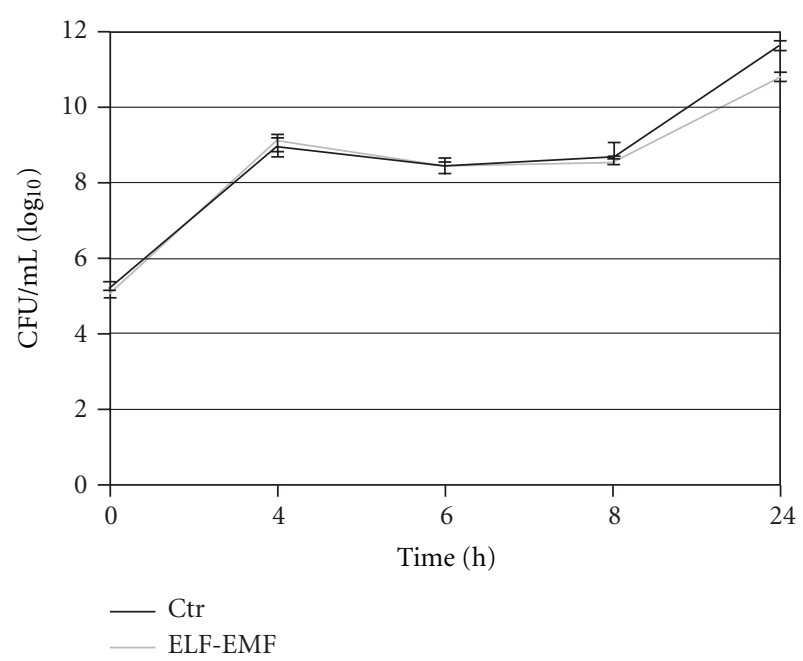

(a)

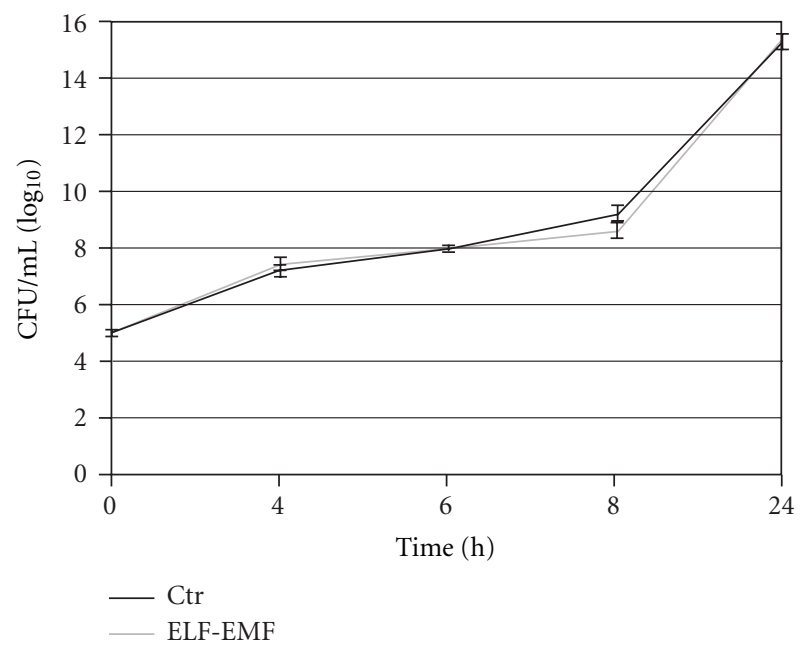

(b)

Figure 2: Effect of ELF-EMF (sinusoidal wave; $2 \mathrm{mT} ; 50 \mathrm{~Hz}$ ) on growth rate of E. coli (a) and P. aeruginosa (b). ELF-EMF: ELF-EMF exposed groups; Ctr: control groups. Data represent means \pm SEM from 3 different experiments.

properties of the extracted proteins, and the sensitivity and resistance to certain antibiotics such as amoxicillin, nalidixic acid, and erythromycin $[45,46]$. These results were in agreement with the work of Stansell and colleagues [55] who found that moderate intensity static fields were able to cause a decrease in the antibiotic sensitivity and resistance of $E$. coli WHMC 4202. Additionally, Belyaev [48] showed that ELF-EMF, under specific conditions of exposure (frequency ranging from $8.5 \mathrm{~Hz}$ to $9 \mathrm{~Hz} ; 0.021 \mathrm{mT}$ ), acted as a nontoxic but cell-growth stimulating agent on E. coli GE499. Again, the exposure of E. coli HB-101 to an ELF-EMF $(25 \mathrm{mT}$; $6 \mathrm{~Hz}$ ) produced a stimulation of cell growth [41]. By contrast, Grosman and colleagues [56] found that static magnetic fields ranging from 0.5 to $4.0 \mathrm{~T}$ had no significant influence on the growth rate and antibiotic sensitivity of $E$. coli and Staphylococcus aureus.
A direct comparison of these studies with our results is difficult because of the dissimilar experimental procedures employed. It is well known that the effects of ELF-EMF generally depend on both physical and biological parameters, including field signal characteristics (frequency, amplitude, wave shape, etc.), duration of exposure, cell metabolic state, genotype, and how long cells are allowed to grow before, during, and after exposure.

However, the apparent ineffectiveness to ELF-EMF exposure was, at least in part, confuted by the evaluations of the growth rate of bacteria in the presence or in the absence of subinhibitory concentration of antibiotics. This choice was not incidental and based on the hypothesis that the influence of ELF-EMF exposure could be bound to some soft modulation of the biological functions not detectable when bacteria were already exposed to excessive changes of stressful environments (MIC values of antibiotics). On the other hand, in absence of antibiotics bacteria may recognize electromagnetic stimulus and respond by activating a selfadjusting mechanism which allow them to maintain physiologically conditions. Thus, a possible cumulative effect could be detectable when bacterial cell was exposed to ELF-EMF and antibiotics at subinhibitory concentration all at once.

Our data demonstrate that the exposure to ELF-EMF significantly influenced the growth rate of $E$. coli and $P$. aeruginosa when incubated in the presence of subinhibitory concentrations of kanamycin $(1 \mu \mathrm{g} / \mathrm{mL})$ and amikacin $(0.5 \mu \mathrm{g} / \mathrm{mL}$ ), respectively (Figure 3$)$. In particular, at 4,6 , and $8 \mathrm{~h}$ of incubation the number of cells was significantly decreased in both strains exposed to ELF-EMF when compared with the control. The percentage of decrease for E. coli was $12 \pm 2,42 \pm 5$, and $13 \pm 2$ at 4,6 , and $8 \mathrm{~h}$, respectively (Figure 3(a)). Similarly, the percentage of decrease for $P$. aeruginosa was $13 \pm 2,22 \pm 3$, and $14 \pm 3$ at 4,6 , and $8 \mathrm{~h}$, respectively (Figure $3(\mathrm{~b})$ ). In both cases (E. coli and $P$. aeruginosa) ELF-EMF seemed to act in a similar way though some differences in the cell response were noted. In fact, at $6 \mathrm{~h}$ of incubation ELF-EMF exerted a more marked inhibitory effect on $E$. coli rather than $P$. aeruginosa. Moreover, at $24 \mathrm{~h}$ of incubation, the number of cells of $P$. aeruginosa significantly increased $(\sim 42 \%)$ in ELF-EMF exposed groups with respect to control groups, indicating a progressive and marked adaptive response to ELF-EMF. On the contrary, at $24 \mathrm{~h}$ of incubation, electromagnetic treatments tend to increase slightly the growth rate of $E$. coli (percentage of increase: $\sim 5 \%$ ) and the values were not significant.

From these data it resulted that ELF-EMF in combination of subinhibitory concentrations of antibiotics may act as stressing factor able to significantly affect the growth rate of bacteria. Moreover, to escape from these altered or stressproducing environments, bacteria can reverse ( $P$. aeruginosa) or abolish (E. coli) their initial responses and seek to resume their normal level of homeostasis.

At this point different questions arise: (1) which cellular mechanism is responsible for coupling ELF-EMF to antibiotics in activating cell response?; (2) which cellular mechanism is involved in mediating the cellular adaptive response; (3) why does $P$. aeruginosa show a different response 


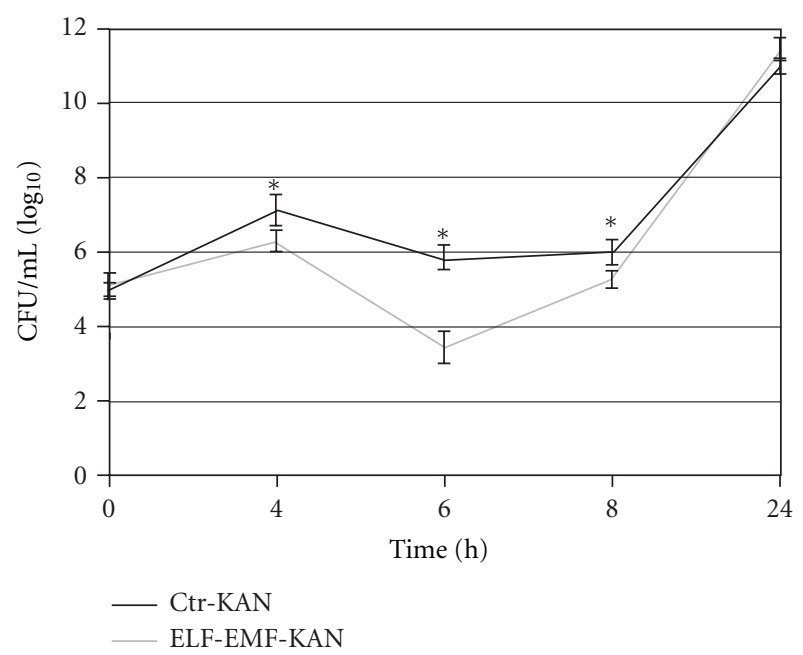

(a)

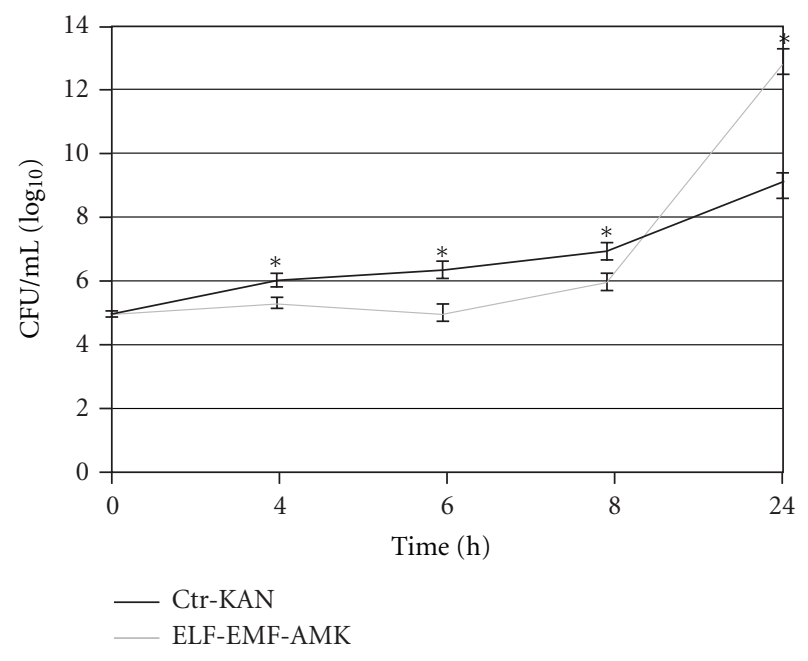

(b)

Figure 3: ELF-EMF (sinusoidal wave; $2 \mathrm{mT}$; $50 \mathrm{~Hz}$ ) influenced the growth rate of E. coli (a) and P. aeruginosa (b) when incubated in the presence of subinhibitory concentration of kanamycin and amikacin, respectively. ELF-EMF-KAN: ELF-EMF exposed groups incubated in the presence of $1 \mu \mathrm{g} / \mathrm{mL}$ kanamycin; Ctr-KAN: control groups incubated in the presence of $1 \mu \mathrm{g} / \mathrm{mL}$ kanamycin; ELFEMF-AMK: ELF-EMF exposed groups incubated in the presence of $0.5 \mu \mathrm{g} / \mathrm{mL}$ amikacin; Ctr-AMK: control groups incubated in the presence of $0.5 \mu \mathrm{g} / \mathrm{mL}$ amikacin. Data represent means \pm SEM from 3 different experiments. ${ }^{*} P<0.05$ (one-way ANOVA followed by Tukey's test).

amplitude respect to E. coli? In this regard, it is possible to hypothesize an interaction between the electromagnetic field and the bacterial uptake process of aminoglycoside antibiotics. It is well known that aminoglycoside antibiotics are cationic molecules which binds to anionic components of the bacterial cell membrane in a reversible and concentrationdependent manner [57]. Therefore, the possibility that ELF-EMF could interfere with the surface charges of the membrane and/or the charge distribution on the antibiotic molecule modifying the rate of antibiotic penetration may exist, in view of the potential role played by ELF-EMF in modulating charge movements on the membrane. In this respect, it has been verified that ELF-EMF can affect membrane functions not only by a local effect on ion fluxes or ligand binding, but also by altering the distribution and/or the aggregation of the intramembrane protein [58-62]. However, we cannot exclude that ELF-EMF could interact with other specific processes that help the adaptation of bacteria to the new environment. In this regard, bacteria are able to respond to environmental stresses by activating suitable inducible systems, such as the DNA repair system, and exploit processes which increase the genetic variability.

Of note, since clinical and research laboratory instruments incorporate so many incontrollable electromagnetic fields, the observation that ELF-EMF did not affect the bacteria antibiotic sensitivity could exclude the possibility of producing alterations in laboratory test results where a high data reproducibility is required.

Further analyses are required to determine the molecular mechanisms underlying our early results. In this regard, it will be interesting to study the influence of different EMF frequency and/or intensity values on bacterial functional parameters to evaluate at which level the adaptive response starts. Moreover, in future studies, experiments involving strains with different genetic background will be investigated to elucidate our observations.

\section{Acknowledgment}

This work was supported by MURST ex 60\% grant from "Ministero dell' Università e della Ricerca Scientifica e Tecnologica."

\section{References}

[1] C. Grassi, M. D’Ascenzo, A. Torsello et al., "Effects of $50 \mathrm{~Hz}$ electromagnetic fields on voltage-gated $\mathrm{Ca} 2+$ channels and their role in modulation of neuroendocrine cell proliferation and death," Cell Calcium, vol. 35, no. 4, pp. 307-315, 2004.

[2] T. Nikolova, J. Czyz, A. Rolletschek et al., "Electromagnetic fields affect transcript levels of apoptosis-related genes in embryonic stem cell-derived neural progenitor cells," FASEB Journal, vol. 19, no. 12, pp. 1686-1688, 2005.

[3] H. Wu, K. Ren, W. Zhao, G. E. Baojian, and S. Peng, "Effect of electromagnetic fields on proliferation and differentiation of cultured mouse bone marrow mesenchymal stem cells," Journal of Huazhong University of Science and Technology, vol. 25, no. 2, pp. 185-187, 2005.

[4] C. Ventura, M. Maioli, Y. Asara et al., "Turning on stem cell cardiogenesis with extremely low frequency magnetic fields," FASEB Journal, vol. 19, no. 1, pp. 155-157, 2005.

[5] L. Huang, L. Dong, Y. Chen, H. Qi, and D. Xiao, "Effects of sinusoidal magnetic field observed on cell proliferation, ion concentration, and osmolarity in two human cancer cell lines," Electromagnetic Biology and Medicine, vol. 25, no. 2, pp. 113126, 2006.

[6] A. Lisi, M. Ledda, E. Rosola et al., "Extremely low frequency electromagnetic field exposure promotes differentiation of pituitary corticotrope-derived AtT20 D16V cells," Bioelectromagnetics, vol. 27, no. 8, pp. 641-651, 2006. 
[7] A. Lisi, M. Ledda, F. De Carlo et al., "Calcium ion cyclotron resonance (ICR) transfers information to living systems: effects on human epithelial cell differentiation," Electromagnetic Biology and Medicine, vol. 27, no. 3, pp. 230-240, 2008.

[8] G. Vianale, M. Reale, P. Amerio, M. Stefanachi, S. Di Luzio, and R. Muraro, "Extremely low frequency electromagnetic field enhances human keratinocyte cell growth and decreases proinflammatory chemokine production," British Journal of Dermatology, vol. 158, no. 6, pp. 1189-1196, 2008.

[9] Z. Schwartz, B. J. Simon, M. A. Duran, G. Barabino, R. Chaudhri, and B. D. Boyan, "Pulsed electromagnetic fields enhance BMP-2 dependent osteoblastic differentiation of human mesenchymal stem cells," Journal of Orthopaedic Research, vol. 26, no. 9, pp. 1250-1255, 2008.

[10] A. Foletti, A. Lisi, M. Ledda, F. De Carlo, and S. Grimaldi, "Cellular ELF signals as a possible tool in informative medicine," Electromagnetic Biology and Medicine, vol. 28, no. 1, pp. 71-79, 2009.

[11] R. Goodman and M. Blank, "Magnetic field stress induces expression of hsp70," Cell Stress and Chaperones, vol. 3, no. 2, pp. 79-88, 1998.

[12] M. de Mattei, N. Gagliano, C. Moscheni et al., "Changes in polyamines, c-myc and c-fos gene expression in osteoblast-like cells exposed to pulsed electromagnetic fields," Bioelectromagnetics, vol. 26, no. 3, pp. 207-214, 2005.

[13] R. Piacentini, C. Ripoli, D. Mezzogori, G. B. Azzena, and C. Grassi, "Extremely low-freauency electromagnetic fields promote in vitro neurogenesis via upregulation of Cav1channel activity," Journal of Cellular Physiology, vol. 215, no. 1, pp. 129-139, 2008.

[14] R. Goodman, A. Lin-Ye, M. S. Geddis et al., "Extremely low frequency electromagnetic fields activate the ERK cascade, increase hsp70 protein levels and promote regeneration in Planaria," International Journal of Radiation Biology, vol. 85, no. 10, pp. 851-859, 2009.

[15] F. Bersani, F. Marinelli, A. Ognibene et al., "Intramembrane protein distribution in cell cultures is affected by $50 \mathrm{~Hz}$ pulsed magnetic fields," Bioelectromagnetics, vol. 18, no. 7, pp. 463469, 1997.

[16] O. Massot, B. Grimaldi, J. M. Bailly et al., "Magnetic field desensitizes 5-HT1B receptor in brain: pharmacological and functional studies," Brain Research, vol. 858, no. 1, pp. 143$150,2000$.

[17] K. Varani, S. Gessi, S. Merighi et al., "Effect of low frequency electromagnetic fields on A2A adenosine receptors in human neutrophils," British Journal of Pharmacology, vol. 136, no. 1, pp. 57-66, 2002.

[18] F. Jia, A. Ushiyama, H. Masuda, G. F. Lawlor, and C. Ohkubo, "Role of blood flow on RF exposure induced skin temperature elevations in rabbit ears," Bioelectromagnetics, vol. 28, no. 3, pp. 163-172, 2007.

[19] X. Q. Ke, W. J. Sun, D. Q. Lu, Y. T. Fu, and H. Chiang, “ $50 \mathrm{~Hz}$ magnetic field induces EGF-receptor clustering and activates RAS," International Journal of Radiation Biology, vol. 84, no. 5, pp. 413-420, 2008.

[20] M. de Mattei, K. Varani, F. F. Masieri et al., "Adenosine analogs and electromagnetic fields inhibit prostaglandin E2 release in bovine synovial fibroblasts," Osteoarthritis and Cartilage, vol. 17, no. 2, pp. 252-262, 2009.

[21] F. Tian, T. Nakahara, K. Wake, M. Taki, and J. Miyakoshi, "Exposure to $2.45 \mathrm{GHz}$ electromagnetic fields induces hsp70 at a high SAR of more than $20 \mathrm{~W} / \mathrm{kg}$ but not at $5 \mathrm{~W} / \mathrm{kg}$ in human glioma MO54 cells," International Journal of Radiation Biology, vol. 78, no. 5, pp. 433-440, 2002.
[22] S. Tofani, D. Barone, M. Cintorino et al., "Static and ELF magnetic fields induce tumor growth inhibition and apoptosis," Bioelectromagnetics, vol. 22, no. 6, pp. 419-428, 2001.

[23] M. T. Santini, A. Ferrante, R. Romano et al., "A $700 \mathrm{MHz} 1 \mathrm{H}-$ NMR study reveals apoptosis-like behavior in human K562 erythroleukemic cells exposed to a $50 \mathrm{~Hz}$ sinusoidal magnetic field," International Journal of Radiation Biology, vol. 81, no. 2, pp. 97-113, 2005.

[24] J. Zhou, G. Yao, J. Zhang, and Z. Chang, "CREB DNA binding activation by a $50 \mathrm{~Hz}$ magnetic field in HL60 cells is dependent on extra- and intracellular Ca2+ but not PKA, PKC, ERK, or p38 MAPK," Biochemical and Biophysical Research Communications, vol. 296, no. 4, pp. 1013-1018, 2002.

[25] C. Morabito, F. Rovetta, M. Bizzarri, G. Mazzoleni, G. Fanò, and M. A. Mariggiò, "Modulation of redox status and calcium handling by extremely low frequency electromagnetic fields in C2C12 muscle cells: a real-time, single-cell approach," Free Radical Biology and Medicine, vol. 48, no. 4, pp. 579-589, 2010.

[26] R. Iorio, S. Delle Monache, F. Bennato et al., "Involvement of mitochondrial activity in mediating ELF-EMF stimulatory effect on human sperm motility," Bioelectromagnetics, vol. 32, no. 1, pp. 15-27, 2011.

[27] K. Zwirska-Korczala, J. Jochem, M. Adamczyk-Sowa et al., "Effect of extremely low frequency electromagnetic fields on cell proliferation, antioxidative enzyme activities and lipid peroxidation in 3T3-L1 preadipocytes-an in vitro study," Journal of Physiology and Pharmacology, vol. 56, no. 6, pp. 101108, 2005.

[28] F. I. Wolf, A. Torsello, B. Tedesco et al., " $50 \mathrm{~Hz}$ extremely low frequency electromagnetic fields enhance cell proliferation and DNA damage: possible involvement of a redox mechanism," Biochimica et Biophysica Acta, vol. 1743, no. 1-2, pp. 120-129, 2005.

[29] M. Simkó, "Cell type specific redox status is responsible for diverse electromagnetic field effects," Current Medicinal Chemistry, vol. 14, no. 10, pp. 1141-1152, 2007.

[30] S. Di Loreto, S. Falone, V. Caracciolo et al., "Fifty hertz extremely low-frequency magnetic field exposure elicits redox and trophic response in rat-cortical neurons," Journal of Cellular Physiology, vol. 219, no. 2, pp. 334-343, 2009.

[31] Y. D. Alipov, I. Y. Belyaev, and O. A. Aizenberg, "Systemic reaction of Escherichia coli cells to weak electromagnetic fields of extremely low frequency," Bioelectrochemistry and Bioenergetics, vol. 34, no. 1, pp. 5-12, 1994.

[32] I. Y. Belyaev, A. Y. Matronchik, and Y. D. Alipov, "The effect of weak static and alternating magnetic fields on the genome conformational state of $E$. coli cells: evidence for the model of phase modulation of high frequency oscillations," in Charge and Field Effects in Biosystems, M. J. Allen, Ed., pp. 174184, World Scientific Publishing Co. PTE Ltd., Singapore, Singapore, 4th edition, 1994.

[33] S. Nakasono, M. Ikehata, T. Koana, and H. Saiki, "A $50 \mathrm{~Hz}$, $14 \mathrm{mT}$ magnetic field is not mutagenic or co-mutagenic in bacterial mutation assays," Mutation Research, vol. 471, no. 12, pp. 127-134, 2000.

[34] L. Strašák, V. Vetterl, and J. Šmarda, "Effects of low-frequency magnetic fields on bacteria Escherichia coli," Bioelectrochemistry, vol. 55, no. 1-2, pp. 161-164, 2002.

[35] L. Strašák, V. Vetterl, and L. Fojt, "Effects of $50 \mathrm{~Hz}$ magnetic fields on the viability of different bacterial strains," Electromagnetic Biology and Medicine, vol. 24, no. 3, pp. 293-300, 2005. 
[36] S. Yonemoto, W. Huang, M. He, Q. He, and L. Yang, "Preliminary study on technology of magnetic field nonthermal sterilization," Transactions of the Chinese Society of Agricultural Engineering, vol. 19, no. 5, pp. 156-160, 2003.

[37] L. Fojt, L. Strašák, V. Vetterl, and J. Šmarda, "Comparison of the low-frequency magnetic field effects on bacteria Escherichia coli, Leclercia adecarboxylata and Staphylococcus aureus," Bioelectrochemistry, vol. 63, no. 1-2, pp. 337-341, 2004.

[38] L. Foit, L. Strašák, and V. Vetterl, "Effect of electromagnetic fields on the denitrification activity of Paracoccus denitrificans," Bioelectrochemistry, vol. 70, no. 1, pp. 91-95, 2007.

[39] L. Fojt, P. Klapetek, L. Strašák, and V. Vetterl, “ 50 Hz magnetic field effect on the morphology of bacteria," Micron, vol. 40, no. 8, pp. 918-922, 2009.

[40] L. Fojt, L. Strasak, and V. Vetterl, "Extremely-low frequency magnetic field effects on sulfate reducing bacteria viability," Electromagnetic Biology and Medicine, vol. 29, no. 4, pp. 177$185,2010$.

[41] I. V. Babushkina, V. B. Borodulin, N. A. Shmetkova et al., "The influence of alternating magnetic field on Escherichia coli bacterial cells," Pharmaceutical Chemistry Journal, vol. 39, no. 8, pp. 398-400, 2005.

[42] O. R. Justo, V. H. Perez, D. C. Alvarez, and R. M. Alegre, "Growth of Escherichia coli under extremely low-frequency electromagnetic fields," Applied Biochemistry and Biotechnology, vol. 134, no. 2, pp. 155-163, 2006.

[43] B. Del Re, F. Bersani, P. Mesirca, and G. Giorgi, "Synthesis of DnaK and GroEL in Escherichia coli cells exposed to different magnetic field signals," Bioelectrochemistry, vol. 69, no. 1, pp. 99-103, 2006.

[44] O. R. Justo, V. H. Pérez, D. C. Alvarez, and R. M. Alegre, "Growth of Escherichia coli under extremely low-frequency electromagnetic fields," Applied Biochemistry and Biotechnology, vol. 134, no. 2, pp. 155-163, 2006.

[45] E.-S. A. Gaafar, M. S. Hanafy, E. T. Tohamy, and M. H. Ibrahim, "Stimulation and control of E. coli by using an extremely low frequency magnetic field," Romanian Journal of Biophysics, vol. 16, no. 4, pp. 283-296, 2006.

[46] E.-S. A. Gaafar, M. S. Hanafy, E. T. Tohamy, and M. H. Ibrahim, "The effect of electromagnetic field on protein molecular structure of E. coli and its pathogenesis," Romanian Journal of Biophysics, vol. 18, no. 2, pp. 145-169, 2008.

[47] L. Cellini, R. Grande, E. Di Campli et al., "Bacterial response to the exposure of $50 \mathrm{~Hz}$ electromagnetic fields," Bioelectromagnetics, vol. 29, no. 4, pp. 302-311, 2008.

[48] I. Belyaev, "Toxicity and SOS-response to ELF magnetic fields and nalidixic acid in E. coli cells," Mutation Research, vol. 722, no. 1, pp. 56-61, 2011.

[49] G. Giorgi, P. Marcantonio, F. Bersani, E. Gavoci, and B. Del Re, "Effect of extremely low frequency magnetic field exposure on DNA transposition in relation to frequency, wave shape and exposure time," International Journal of Radiation Biology, vol. 87 , no. 6, pp. 601-608, 2011.

[50] A. Inhan-Garip, B. Aksu, Z. Akan, D. Akakin, A. N. Ozaydin, and T. San, "Effect of extremely low frequency electromagnetic fields on growth rate and morphology of bacteria," International Journal of Radiation Biology, vol. 87, no. 12, pp. 11551161, 2011.

[51] S. B. Levy, "Antibiotic resistance: consequences of inaction," Clinical Infectious Diseases, vol. 33, supplement 3, pp. S124S129, 2001.
[52] K. Bush, P. Courvalin, G. Dantas et al., "Tackling antibiotic resistance," Nature Reviews Microbiology, vol. 9, no. 12, pp. 894-896, 2011.

[53] Clinical and Laboratory Standards Institute, Performance Standards for Antimicrobial Susceptibility Testing; Twenty-First International Supplement M100-S21, Clinical and Laboratory Standards Institute, Wayne, Pa, USA, 2010.

[54] F. D. Schoenknecht, L. D. Sabath, and C. Thornsberry Jr, "Susceptibility tests: special test," in Manual of Clinical Microbiology, E. H. Lennette, A. Balows, W. J. Hansler Jr, and H. J. Shadomy, Eds., America Society for Microbiology, Washington, DC, USA, 4th edition, 1985.

[55] M. J. Stansell, W. D. Winters, D. Robert H, and B. K. Dart, "Increased antibiotic resistance of $E$. coli exposed to static magnetic fields," Bioelectromagnetics, vol. 22, no. 2, pp. 129137, 2001.

[56] Z. Grosman, M. Kolár, and E. Tesaríková, "Effects of static magnetic field on some pathogenic microorganisms," Acta Universitatis Palackianae Olomucensis Facultatis Medicae, vol. 134, pp. 7-9, 1992.

[57] H. W. Taber, J. P. Mueller, P. F. Miller, and A. S. Arrow, "Bacterial uptake of aminoglycoside antibiotics," Microbiological Reviews, vol. 51, no. 4, pp. 439-457, 1987.

[58] J. Walleczek, "Electromagnetic field effects on cells of the immune system: the role of calcium signaling," FASEB Journal, vol. 6, no. 13, pp. 3177-3185, 1992.

[59] K. J. McLeod, C. T. Rubin, and H. J. Donahue, "Electromagnetic fields in bone repair and adaptation," Radio Science, vol. 30, no. 1, pp. 233-244, 1995.

[60] F. Bersani, F. Marinelli, A. Ognibene et al., "Intramembrane protein distribution in cell cultures is affected by $50 \mathrm{~Hz}$ pulsed magnetic fields," Bioelectromagnetics, vol. 18, no. 7, pp. 463469, 1997.

[61] R. Tonini, M. D. Baroni, E. Masala, M. Micheletti, A. Ferroni, and M. Mazzanti, "Calcium protects differentiating neuroblastoma cells during $50 \mathrm{~Hz}$ electromagnetic radiation," Biophysical Journal, vol. 81, no. 5, pp. 2580-2589, 2001.

[62] I. Marchionni, A. Paffi, M. Pellegrino et al., "Comparison between low-level $50 \mathrm{~Hz}$ and $900 \mathrm{MHz}$ electromagnetic stimulation on single channel ionic currents and on firing frequency in dorsal root ganglion isolated neurons," Biochimica et Biophysica Acta, vol. 1758, no. 5, pp. 597-605, 2006. 

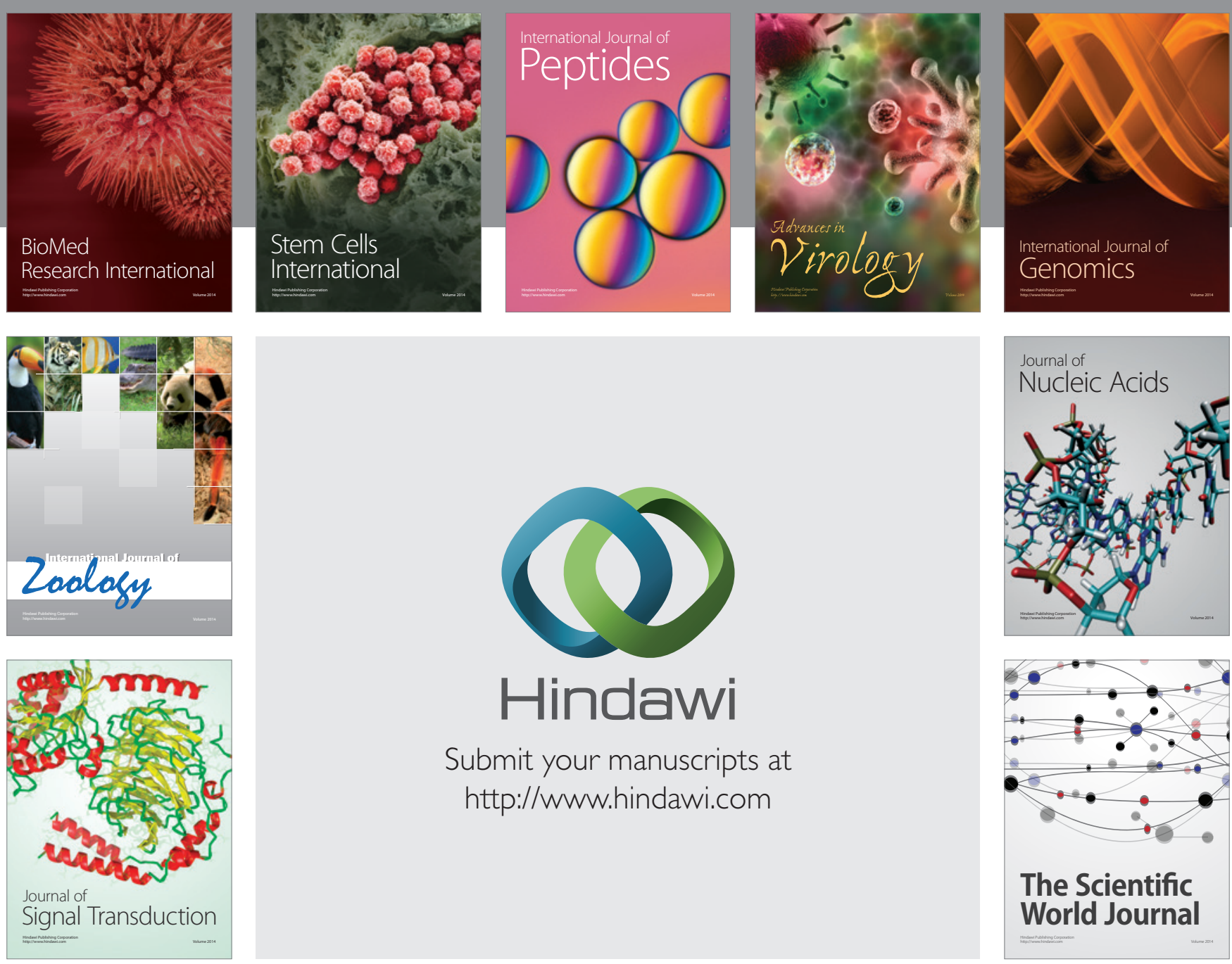

Submit your manuscripts at

http://www.hindawi.com
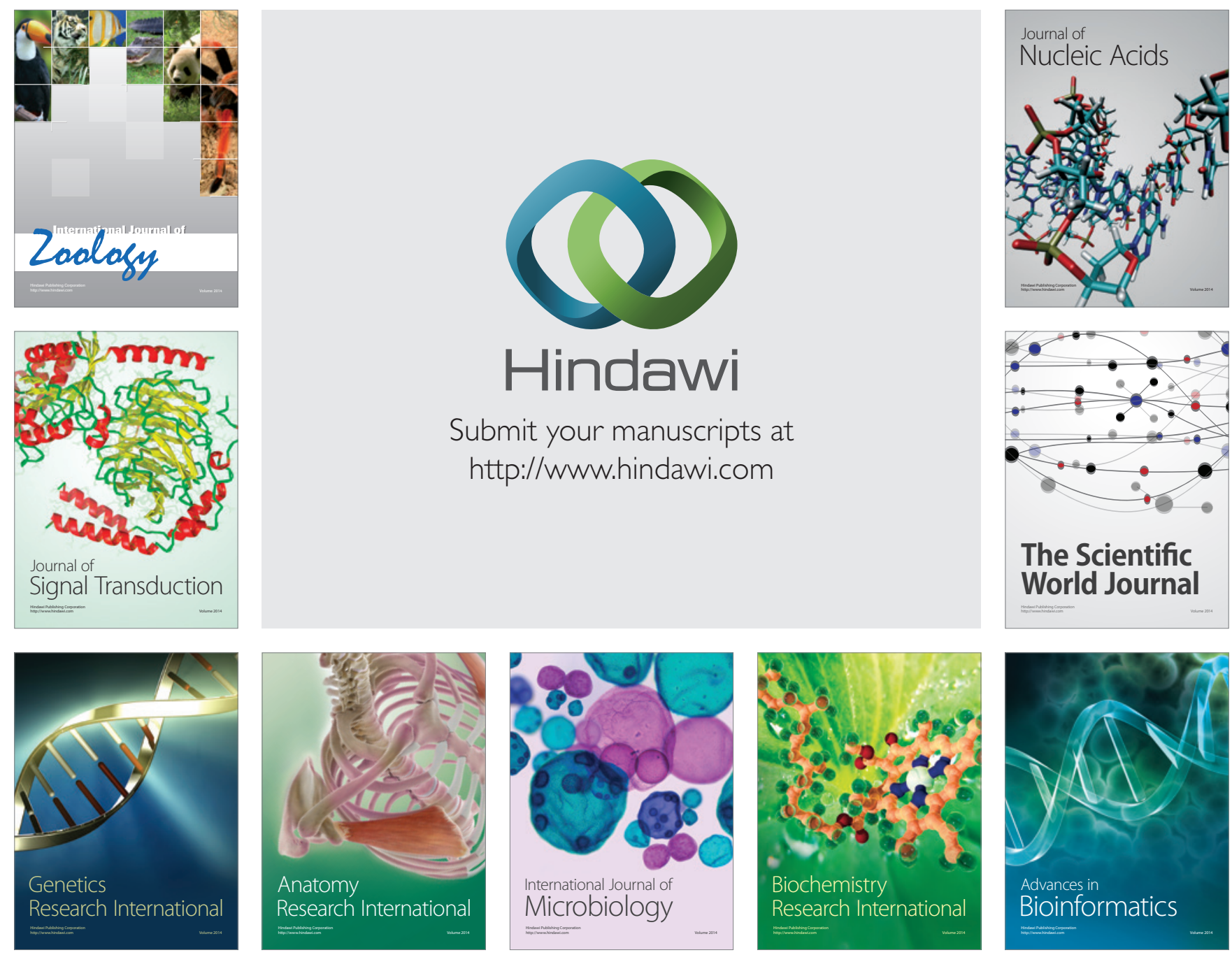

The Scientific World Journal
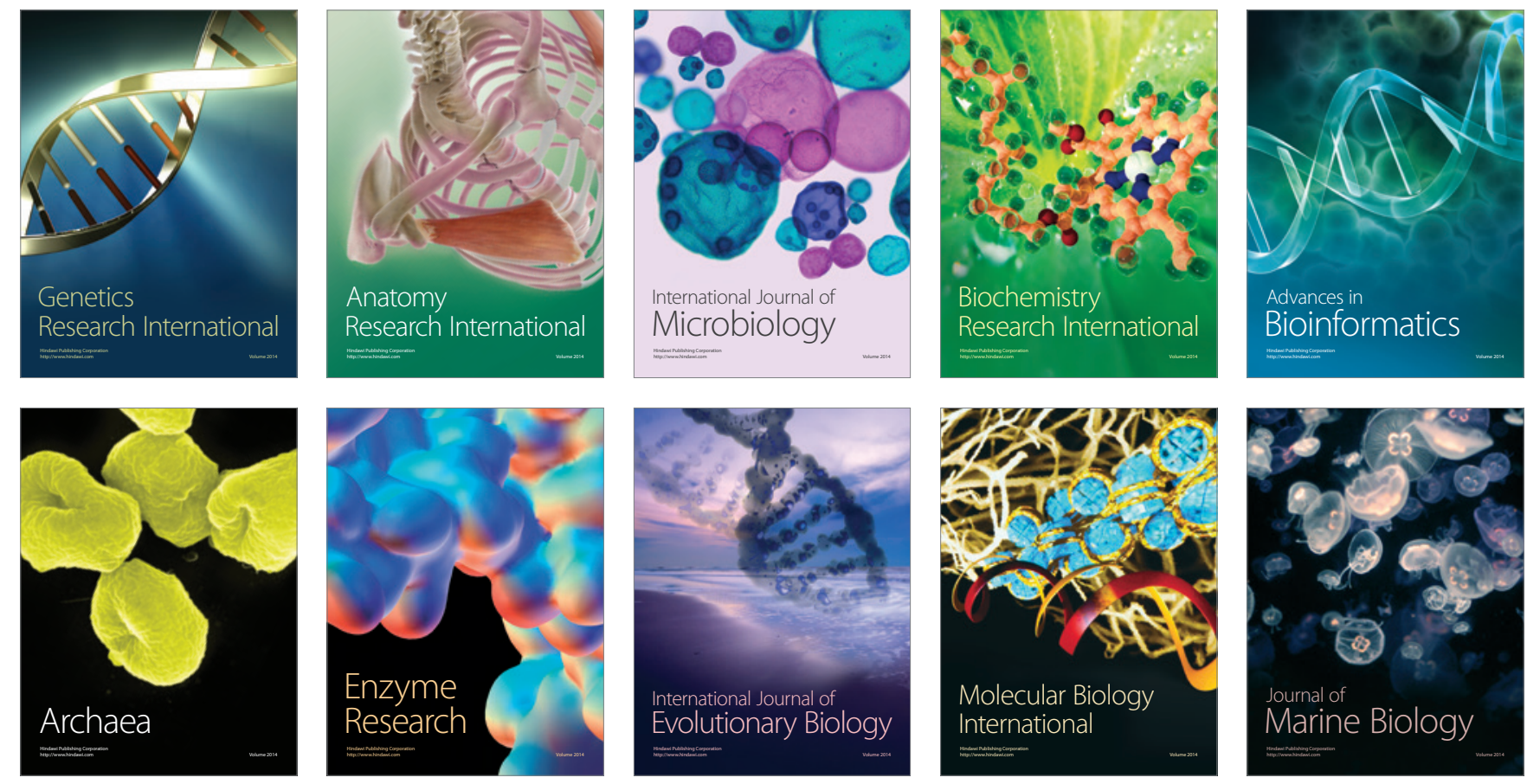